\title{
Indicações geográficas e a multifuncionalidade da agricultura
}

\author{
Valdinho Pellin ${ }^{1}$
}

\section{RESUMO}

Indicações Geográficas (IGs) podem ser entendidas como estratégias de desenvolvimento a partir do momento que possibilitam agregar valor a produtos ou serviços que tem características próprias relacionadas ao território ao qual estão inseridas. Podem representar também valorização das tradições locais associadas ao fortalecimento de uma identidade cultural própria. Metodologicamente o trabalho ancora-se em pesquisa bibliográfica de caráter descritivo e busca identificar na literatura nacional e internacional a relação entre IGs e desenvolvimento territorial rural, apontando suas principais contribuições e desafios. Concluiu-se que IGs podem contribuir para fortalecimento do desenvolvimento rural, estimulando a multifuncionalidade da agricultura, aumentando a renda dos produtores, gerando emprego e contribuindo para manter e fortalecer tradições e modos de produção locais. Os principais desafios relacionam-se a estruturação de arranjos institucionais que articule de maneira eficiente os atores envolvidos; ao alto custo financeiro para reconhecer e manter uma IG e ao perigo da mercantilização dos processos produtivos que coloca em risco a tipicidade dos produtos ligados à sua origem.

Palavras chaves: Indicação Geográfica; Desenvolvimento Territorial Rural; Multifuncionalidade da Agricultura.

\section{Geographical Indication and the Multi functionality of agriculture.}

\begin{abstract}
Geographical Indications (GIs) can be understood as development strategies from the moment that allow adding value to products or services that has its own characteristics related to the territory to which they belong. They can also represent appreciation of local traditions associated with the strengthening of its own cultural identity. Methodologically the work was anchored in literature descriptive and seeks to identify in national and international literature the relationship between GIs and rural territorial development, pointing his main contributions and challenges. It was concluded that GIs can contribute to strengthening rural development, stimulating the multi functionality of agriculture, increasing farmers' income, generating employment and contributing to maintaining and strengthening local traditions and modes of production. The main challenges relate to the structuring of institutional arrangements that articulate efficiently the actors involved; the high financial cost to recognize and maintain an IG and the danger of the commodification of production processes that jeopardizes the typical characteristics of products linked to their origin.
\end{abstract}

Keywords: Geographical Indication; Rural Territorial Development; Multi functionality of agriculture

\footnotetext{
1 Graduado em Economia. Mestre e Doutorando pelo Programa de Pós-Graduação em Desenvolvimento Regional da Universidade Regional de Blumenau (PPGDR/FURB). Pesquisador do Núcleo de Políticas Públicas do PPGDR/FURB. Bolsista Capes. E-mail: prof.pellin@tpa.com.br
} 


\section{INTRODUÇÃO}

A busca incessante por alternativas que possam impulsionar o desenvolvimento local tem sido alvo de discussões nos últimos tempos. O objetivo a ser perseguido perpassa por alcançar desenvolvimento eficaz que esteja alicerçado num tripé que envolve crescimento econômico, justiça social e preservação ambiental. Para que isso se torne realidade é necessário implementar estratégias para diminuir desigualdades sociais e conquistar uma melhoria na qualidade de vida da população autóctone. Ganha força, portanto, a ideia do desenvolvimento endógeno, onde a comunidade desperta para aproveitamento de potencialidades locais, até então exploradas inadequadamente ou de forma incipiente.

Como ressaltam Vieira e Cunha (2002), há necessidade de tentar buscar um novo modelo de desenvolvimento para a sociedade atual. Um desenvolvimento local integrado e sustentável que busque harmonização dos objetivos ligados ao crescimento econômico, equidade social, democratização dos processos decisórios e cultivo da prudência ecológica. Nesta mesma linha de raciocínio Sachs (2003) destaca que o planejamento para o desenvolvimento com enfoque territorial tem ganhado importância. No Brasil experiências inovadoras vêm surgindo, com destaque para as discussões acerca da implementação de um Desenvolvimento Local Integrado e Sustentável (DLIS) que define estratégias locais de desenvolvimento através do envolvimento das comunidades, no âmbito de instâncias coletivas de participação, tais como conselhos e fóruns de desenvolvimento.

Em relação ao desenvolvimento territorial, conceito que será clarificado no decorrer do artigo, é importante destacar que a noção de território vai além da questão geográfica. Nela insere-se, por exemplo, os atores e as relações institucionais que os inter-relacionam, principalmente relações de poder. Como destaca Carriàre e Cazella (2006), territórios são realidades em movimento, nas quais imperam as relações. A noção de território designa aqui resultado da confrontação dos espaços individuais dos atores nas suas dimensões econômicas, socioculturais e ambientais.

Partindo do conceito de Carriàre e Cazella (2006), os territórios rurais também podem tornar-se dinâmicos quando investem na multifuncionalidade de seus espaços. Pequenos produtores rurais podem utilizar-se da produção orgânica como alternativa para agregar valor a seus produtos e tornar sua atividade mais rentável. Outro exemplo é o desenvolvimento de atividades não rurais em espaços rurais como é o caso do turismo.

Recentemente emergiram importantes discussões voltadas as contribuições que Indicações Geográficas (IGs) poderiam oferecer ao desenvolvimento rural. Amplamente 
consolidadas na União Europeia $^{2}$ e ainda pouco reconhecidas no Brasil e América do Sul, poderiam tornar-se alternativa importante para dinamizar atividades agrícolas tradicionais, principalmente aquelas desenvolvidas em minifúndios. É neste contexto que se pretende discutir neste artigo, a partir de uma revisão bibliográfica, as contribuições que IGs podem oferecer ao desenvolvimento territorial rural, bem como seus principais desafios.

\section{METODOLOGIA}

Este artigo valeu-se de uma pesquisa bibliográfica de caráter descritivo. A principal vantagem da pesquisa bibliográfica reside no fato de permitir ao investigador a cobertura de uma gama de fenômenos muito mais ampla do que aquela que pesquisaria diretamente (GIL, 2010). O material consultado abrange o referencial já tornado público em relação ao tema estudado, reunindo-se assim conhecimento sobre temática pesquisada (RAUPP e BAUREN, 2003). Em relação aos principais desafios das IGs para o desenvolvimento territorial rural optou-se por amparar-se em discussões relacionadas a experiências de IGs originárias da vitivinicultura, por entender que são as mais representativas no Brasil e no mundo e por congregar em um mesmo espaço rural grandes, médios e pequenos produtores.

O artigo inicia com uma breve contextualização em relação ao desenvolvimento territorial em espaços rurais e multifuncionalidade da agricultura. Em seguida, aborda especificamente a questão das IGs e suas contribuições para o desenvolvimento territorial rural, finalizando com uma breve descrição de seus principais desafios.

\section{DESENVOLVIMENTO TERRITORIAL RURAL E MULTIFUNCIONALIDADE DA AGRICULTURA}

O conceito de desenvolvimento territorial ${ }^{3}$ rompe com uma tradição mais antiga de estudos sobre o desenvolvimento regional e não dispõe ainda de um arcabouço doutrinário ou de teorias já estabelecidas. Articula duas noções: desenvolvimento e território. O território não se define por sua escala, e sim pelo modo de organização e pela maneira segundo qual atores constitutivos dos territórios conseguem coordenar suas ações (JEAN, 2010). Ao corroborar com Jean (2010), Pecqueur (2005) destaca que o desenvolvimento territorial

\footnotetext{
${ }^{2}$ Sobretudo as originárias da vitivinicultura.

${ }^{3}$ Nessa discussão emerge também o conceito de desenvolvimento territorial solidário que, de acordo com Jean (2010 p. 60), repousa no reconhecimento dos direitos das comunidades rurais de se desenvolver valorizando os recursos disponíveis em seu território.
} 
designa todo processo de mobilização dos atores que leve à elaboração de uma estratégia de adaptação aos limites externos, na base de uma identificação coletiva com uma cultura e um território.

No Brasil, o debate em torno do desenvolvimento territorial sustentável no meio rural intensifica-se não apenas como mais uma questão de corte setorial, mas como um assunto que interessa a toda sociedade. O meio rural passa a ser visto como um palco para criação de dinâmicas inovadoras de desenvolvimento. Isso ocorreu, principalmente nas últimas décadas, quando a maioria da população brasileira observa o crescimento de uma urbanização caótica e excessiva que se torna cada vez mais problemática em função do agravamento do êxodo rural, sobretudo da população jovem (ANDION, 2010).

Aliás, o processo de urbanização sempre estará presente nas discussões relacionadas ao desenvolvimento no meio rural. A verdade é que, como bem destaca Martini (1993), a redistribuição da população sobre o espaço obedece à evolução da localização e reestruturação da atividade econômica. Ou seja, como a concentração espacial da grande maioria das atividades econômicas localiza-se nos grandes centros, é lá que se concentra também a maior parte da população.

Para tentar entender este contexto, o da urbanização, é importante entender a trajetória da agricultura no Brasil e principalmente as principais fases de sua modernização. Martini (1991) destaca que no Brasil, as constantes super safras contribuíram nos últimos anos para fortalecer a imagem de uma agricultura moderna, autossuficiente e de consequências sociais inevitavelmente benéficas. No entanto, ao analisar as principais fases da modernização ${ }^{4}$ da agricultura no país observou-se que as políticas públicas beneficiavam grandes produtores rurais através de subsídios ou políticas específicas para determinados setores e renegavam a um segundo plano os pequenos produtores. Entendia-se que importante era beneficiar a produção de grande escala e destinada à exportação.

Em nome do progresso, agro ecossistemas foram transformados, culturas tradicionais foram distorcidas e estruturas sociais tiveram suas bases modificadas. Agricultores que não tinham suficiente acesso à terra e outros recursos produtivos não se ajustaram às condições ecológicas e sócio ambientais da agricultura convencional e permaneceram fora da dinâmica do desenvolvimento rural. (MOREIRA e CARMO, 2004)

\footnotetext{
${ }^{4} \mathrm{O}$ autor destaca pelo menos três fases importantes da modernização agrícola: a modernização conservadora (1965 - 1979); a crise e retração $(1980$ - 1984) e a recuperação e super safras (1985 - 1989). Em todas estas fases o Estado teve um papel decisivo (MARTINI, 1991).
} 
Entretanto, a pequena produção também tem sua importância. Faz uso mais intensivo de todos os fatores à sua disposição, aproveita uma parcela maior de sua terra, emprega mais mão-de-obra e, em alguns casos, tem uma produção por hectare muito maior do que conglomerados e latifúndios. Além disso, é possível conceber e estimular arranjos de estrutura produtiva que aproveitem as vantagens ${ }^{5}$ da propriedade familiar pelo lado da oferta de trabalho, para aumentar a produtividade (MARTINI, 1991).

Portanto, o pequeno produtor rural também possui importância significativa na agricultura. É necessário incentivar sua permanência nas áreas rurais evitando o êxodo rural que provoca processos de urbanização descontroladas nas grandes cidades ${ }^{6}$. Além disso, em razão das vantagens comparativas do pequeno produtor em determinadas culturas e regiões bem como potencialidades inexploradas (formas associativas) faz todo o sentido o governo investir recursos governamentais explorando estas alternativas e fortalecendo com isso a agricultura familiar ${ }^{7}$.

Neste cenário, emerge a importância da multifuncionalidade da agricultura, ou seja, além das produções tradicionais, agricultores tem a oportunidade de inovar e investir no desenvolvimento de novas atividades que tem relação direta com o meio rural, como por exemplo, a agroecologia, a produção de pequenas frutas, a piscicultura, ou relação indireta como o turismo. Para Jean (2010), a noção de multifuncionalidade dos territórios rurais, ou da agricultura, está se tornando um conceito muito popular e que faz surgir, com novas roupagens, uma antiga realidade do mundo rural, ou seja, as diferentes funções que ele exerce.

$\mathrm{Na}$ multifuncionalidade da agricultura, a agroecologia pode desempenhar um papel de destaque. Parafraseando Moreira e Carmo (2004), ela representa uma forma de abordar a agricultura que incorpora cuidados especiais relativos ao ambiente, aos problemas sociais e à sustentabilidade ecológica dos sistemas de produção. Entretanto, para alcançar resultados positivos torna-se necessário a elaboração de um plano de desenvolvimento rural sustentado em bases agroecológicas, definindo-se como um dos princípios a utilização do conhecimento local vinculado aos sistemas tradicionais de manejo ${ }^{8}$ dos recursos naturais. Ou seja, é o conhecimento local juntamente com o cientifico que pode aportar soluções realmente sustentáveis para a região considerada. Outro princípio é a pluriatividade, seletividade e

\footnotetext{
${ }^{5}$ Uma alternativa para viabilizar as vantagens competitivas das pequenas propriedades rurais estaria no estimulo a construção de experiências associativas. Estes estímulos deveriam partir do Estado.

${ }^{6} \mathrm{Ou}$ ainda processos de litoralização, como é o caso de Santa Catarina.

7 Atualmente existe consenso de que o PRONAF - Programa Nacional de Fortalecimento da Agricultura Familiar é um importante instrumento de financiamento da pequena propriedade rural com resultados bastante positivos.

${ }^{8}$ Assim como prevê as Indicações Geográficas.
} 
complementaridade de rendas. Um exemplo disso poderia ser o fortalecimento do turismo rural para produzir rendas complementares à renda agrícola, por meio de estruturas associativas dos agricultores locais, gerando laços de solidariedade, e tomando especial cuidado com a valorização da cultura local.

Além disso, outras características podem tornar o espaço rural atraente. Veiga (2005) defende que encantos como paisagens, ar puro, água limpa, silêncio, tranquilidade são muito valorizados por aposentados, turistas, esportistas e constituem uma importante fonte de vantagens comparativas na economia rural. Há muitas razões para se afirmar que está em curso uma forte revalorização da ruralidade, em vez de sua supressão por uma suposta completa urbanização. São rurais as amenidades que já sustentam o novo dinamismo interiorano dos países avançados. O valor do espaço rural está cada vez mais ligado a tudo que o distingue do espaço urbano. Ocorre o nascimento de uma valorização da ruralidade, possível de ser observada pela forte atração pelos espaços rurais nas sociedades desenvolvidas ${ }^{9}$.

Neste ambiente, surgem experiências ${ }^{10}$ de desenvolvimento territorial em espaços rurais que buscam utilizar potencialidades locais para promover melhoria da qualidade de vida da população envolvida. Estas experiências geralmente são incentivadas por políticas públicas tanto a nível federal quanto a nível estadual e municipal. Um exemplo de política pública com bons resultados é a Lei Federal n 11.947/2009 que determina a utilização de no mínimo $30 \%$ dos recursos repassados pelo $\mathrm{FNDE}^{11}$ para a compra de produtos da agricultura familiar.

\subsection{Principais contribuições das IGs para o desenvolvimento territorial rural}

As $\mathrm{IGs}^{12}$, consolidadas na União Europeia e ainda pouco reconhecidas na América do Sul e no Brasil, podem ser entendidas como uma possibilidade de agregação de valor a

\footnotetext{
${ }^{9}$ A cidade e o campo se casaram (VEIGA, 2005).

${ }^{10}$ Carneiro e Rocha (2010) destacam projetos coletivos de agricultores familiares da região serrana do Estado do RJ, especificamente nos municípios de Nova Friburgo, Sumidouro, Duas Barras, Bom Jardim e Teresópolis. Nesta região a horticultura é responsável pela produção de $90 \%$ de olerícolas do Estado. Os projetos chamados de "Desenvolvimento Territorial" são implementados pela Secretaria de Desenvolvimento Territorial (SDT) vinculada ao Ministério do Desenvolvimento Agrário (MDA).

${ }^{11}$ O Fundo Nacional de Desenvolvimento da Educação tem como objetivo disciplinar o investimento de recursos financeiros em programas e projetos ligados a educação fundamental.

${ }^{12}$ No Brasil, as Indicações Geográficas são regidas pela Lei de Propriedade Industrial (Lei n 9.279/96) e pela Resolução 75/00 do Instituto Nacional de Propriedade Industrial (INPI). De acordo com a legislação existem dois tipos de Indicação Geográfica: a Indicação de Procedência (IP) que é considerada quando a área geográfica é conhecida como centro de extração, produção ou fabricação de determinado produto ou de prestação de
} 
produtos ou serviços que tem características próprias relacionadas ao território ao qual estão inseridas. Essa agregação de valor pode representar um aumento na renda dos produtores envolvidos seja através do aumento no preço dos produtos oferecidos ou aumento do volume de vendas ou na conquista de novos mercados. Representam também uma valorização das tradições locais associadas ao fortalecimento de uma identidade cultural própria

Trata-se de instrumento de valorização de tradições, costumes, saberes, práticas e outros bens imateriais associados à identidade territorial. Utilizada pelos produtores como uma maneira de agregar valor e acessar novos mercados, e reputadas pelos consumidores como mecanismo de garantia de qualidade as IGs são consideradas como potenciais instrumentos de desenvolvimento territorial, posto que possibilitam exploração de ativos intangíveis de difícil transposição para outros territórios, constituindo uma vantagem competitiva em mercados cada vez mais marcados pela diferenciação de produtos (NIEDERLE, 2009).

Nesta mesma esteira de raciocínio, Dullius (2009) reforça que IGs valorizam o território e constituem-se em importante estratégia de agregação de valor aos produtos locais, possibilitando maior competitividade. Além disso, por estarem pautadas nos saberes, modo de ser e de fazer local, servem de apoio para preservação do patrimônio material e imaterial. Também representam uma importante ferramenta para o desenvolvimento territorial ao permitirem que territórios promovam seus produtos através da autenticidade da produção ou peculiaridades ligadas a sua história, cultura ou tradição, estabelecendo o direito reservado aos produtores estabelecidos no referido território.

Caldas, Cerqueira e Perin (2005) que aproximam a ideia de IG com a de Arranjos Produtivos Locais, onde as duas podem ser consideradas como estratégias de desenvolvimento local, destacam que as IGs, embora ainda em fase embrionária no Brasil ${ }^{13}$ podem ser entendidas como uma qualificação para o desenvolvimento do Arranjo Produtivo, por incluir em seus critérios, físicos, sociais e subjetivos, as características essenciais de uma nova forma de olhar o território.

$\mathrm{Na}$ União Europeia este instituto é antigo e difundido em muitos produtos ${ }^{14}$, como o mármore da região de Carrara e o presunto de Parma, na Itália, ou os queijos da região de

determinado serviço e a Denominação de Origem (DO), que é identificada quando as qualidades ou características do produto decorrem exclusiva ou essencialmente ao meio geográfico, incluindo fatores naturais e humanos (CRUZ et al s.d).

${ }^{13}$ O Instituto Nacional de Propriedade Industrial reconheceu até março de 2015, 42 Indicações Geográficas no Brasil. Destas, 34 são Indicações de Procedência e 08 são Denominação de Origem. Rio Grande do Sul, Minas Gerais e Rio de Janeiro são os estados que, respectivamente, apresentam o maior número de IGs reconhecidas.

${ }^{14}$ A União Europeia tem aproximadamente 2.921 produtos registrados (SILVA et al, 2012) 
Roquefort na França, a massa de pão de Toledo na Espanha e milhares de outros.Importante destacar que na Europa, esse tipo de dispositivo de diferenciação, é conhecido como $\mathrm{DOP}^{15}$ (Denominação de Origem Protegida) ou IGP (Indicação Geográfica Protegida) e contempla principalmente produtos agroalimentares que podem ser oriundos de transformação agroindustrial ou produtos in natura (SILVA, et al 2012). Na América do Sul destaca-se o café da Colômbia, o pisco no Chile e Peru e na América Central os charutos cubanos. Embora seja um instituto muito difundido em diversos países, no Brasil ainda que a legislação faculte a criação de IGs em produtos e serviços, as iniciativas ainda são incipientes, porém, representativas.

Das iniciativas reconhecidas pelo Instituto Nacional de Propriedade Industrial (INPI), muitas possuem relação direta ou indireta com espaços rurais como por exemplo: café da região do Cerrado Mineiro, vinho tinto, branco e espumante do Vale dos Vinhedos (RS), carne bovina e seus derivados do Pampa Gaúcho e da Campanha Meridional (RS), arroz irrigado do Litoral Norte Gaúcho e uvas de mesa e manga do Vale do Submédio São Francisco. Recentemente o Estado de Santa Catarina obteve o registro da primeira Indicação Geográfica. Trata-se dos Vales da Uva Goethe ${ }^{16}$ que recebeu o registro devido a qualidade, tipicidade e identidade do vinho da uva Goethe com a região de Urussanga (SC).

Outro fator importante que necessita ser destacado refere-se às atividades complementares que podem surgir após a conquista de uma IG. Um exemplo são as atividades voltadas ao turismo. Após a conquista da IG, o Vale dos Vinhedos ${ }^{17}$ estruturou propostas de roteiros pelas vinícolas (enológico, gastronômico e cultural) aumentando significativamente o fluxo de turistas na região e complementando a renda dos produtores, principalmente das pequenas vinícolas. Este exemplo pretende ser seguido pelos pequenos produtores rurais dos Vales da Uva Goethe da região de Urussanga - SC que também estão iniciando um trabalho voltado ao desenvolvimento da atividade turística paralelamente a atividade da produção do vinho.

\footnotetext{
${ }^{15}$ Para que um produto leve a DOP todas as fases de produção devem realizar-se dentro de uma zona delimitada, sendo que as características do produto dependem exclusivamente, ou essencialmente, de sua origem geográfica. No caso da IGP ao menos uma das fases da produção deve realizar-se numa determinada zona ou território, sendo que o vínculo com a mesma deve estar justificado pelo fato de estar relacionado a uma qualidade específica, reputação ou outra característica do produto (SILVA et al, 2012)

${ }^{16}$ O site da PROGOETHE: $h t t p: / / w w w . p r o g o e t h e . c o m . b r /$, pode dar uma ideia da importância da conquista da IG da do Vale da Uva Goethe para o município de Urussanga e para toda a região.

17 Para entender a importância da IG no desenvolvimento da região do Vale dos Vinhedos, verificar: http://www.valedosvinhedos.com.brl
} 


\subsection{Principais desafios das IGs para o desenvolvimento territorial rural}

Embora a literatura especializada demonstre que as IGs podem contribuir para fortalecer regiões economicamente frágeis ou pouco desenvolvidas ainda existem suspeitas em relação a sua eficiência. Froehlich et al (2010) destacam que existe forte desconfiança por parte de expressivos setores e atores ligados a agricultura familiar sobre a capacidade das IGs de promover o desenvolvimento, visualizando nelas um caráter inerentemente excludente, voltado a favorecer grupos socioeconômicos já privilegiados (agronegócio), em função do tipo de mercado que permite acessar e das condições para sua obtenção.

De modo geral, processos de implementação de IGs e sua consolidação podem representar tanto uma ameaça quanto uma oportunidade ao desenvolvimento territorial sustentável, promovendo (respectivamente) maior exclusão ou maior integração social. O seu resultado depende principalmente do modo de governança local, bem como da mobilização de recursos territoriais, aonde a associação ${ }^{18}$ assume o papel principal (VELLOSO, 2008).

Entende-se que processos de obtenção das IGs podem tornar-se excludentes, quando o arranjo estruturado é formado por empreendimentos com níveis de produção e estrutura, muito diferentes. Neste caso, interesses econômicos dos maiores empreendimentos podem se impor aos menores, bem como processos de tomadas de decisão. Além disso, de acordo com Niederle (2011), em virtude das dinâmicas de mercado, as IGs, em alguns casos, podem estar sendo readequadas para catalisar inovações técnicas e organizacionais que colocam em risco a tipicidade dos produtos ligados à sua origem.

Flores apud Niederle (2009), que efetua uma importante análise da experiência do Vale dos Vinhedos destaca que, no caso específico dessa experiência, a individualização das vinícolas familiares decorrentes da preponderância do interesse econômico estaria desestabilizando as relações de confiança historicamente estabelecidas, inibindo a constituição de uma dinâmica de desenvolvimento territorial.

Reforçando este ponto de vista, Sacco dos Anjos e Caldas (2010) lembram que as dificuldades pelo que passa o Vale dos Vinhedos estão relacionadas à necessidade de conciliar interesses públicos e privados do setor com as bases de uma estratégia de desenvolvimento territorial sustentável. Além disso, outra dificuldade é o excessivo protagonismo das grandes vinícolas devido a sua influência política e econômica no âmbito local e regional.

18 A Indicação Geográfica deve ser solicitada por uma entidade coletiva que represente todos os atores envolvidos no processo. 
Outra crítica importante é o perigo da mercantilização nos processos de produção que podem colocar em risco a tipicidade dos produtos ligados à sua origem. Este risco é destacado por Niederle (2011) que efetua uma análise comparando algumas regiões vitivinícolas do Brasil e da França. Segundo o autor, as IGs tem sido readequadas para catalisar inovações técnicas ${ }^{19}$ e organizacionais que podem colocar em risco modos de produção tradicionais.

Os vinhedos de Beaujolais, na França, são exemplos disso. Possuem uma cepagem única e rara para vinhos tintos: o gamay noir à jus blanc. A uva é colhida à mão para preservar os grãos maduros intactos até a cubagem. Ocorre que a produção desse tipo de uva requer uma grande quantidade de mão-de-obra e um rigoroso controle dos solos o que representa altíssimos custos de produção em relação aos outros vinhedos franceses e estrangeiros. Para tentar amenizar estes custos foram incentivadas modificações nas práticas de cultivo a fim de tornar a produção mais competitiva. Uma alteração que está sendo implantada e ainda gera polêmica é a colheita mecanizada ${ }^{20}$ que, para alguns produtores, pode influência no sabor do vinho (NIEDERLE, 2011).

No Brasil também existem exemplos de modificações na produção. A produção vitivinícola nacional foi construída a partir do sistema de condução em latada (ou pérgola), o mesmo utilizado na Itália pelos agricultores imigrantes que colonizaram as principais regiões do Rio Grande do Sul. No entanto, quando foram introduzidas outras cultivares viníferas este sistema demonstrou-se pouco viável e foi substituído por novos modos de condução o que provocou uma redefinição das paisagens (NIEDERLE, 2011).

Portanto, é possível verificar que ao mesmo tempo em que as IGs destacam o vínculo do vinho com o terroir e o patrimônio local, incitam transformações mais ou menos radicais dos métodos de viticultura e vinificação, das relações de produção e da própria paisagem. Não raro, as mudanças sugeridas pelos projetos, sob a pressão de um mercado cada vez mais contingente e competitivo, ameaçam a tipicidade do produto ligado à sua origem. Em resposta a mudança do consumo mundial de vinhos, a proliferação de normas e regras de produção pode vir associada à padronização dos processos produtivos e homogeneização do produto (NIEDERLE, 2011).

\footnotetext{
${ }^{19}$ Um exemplo é a substituição de cepas tradicionais por variedades mais resistentes ao clima, que apresentam uma maior produção por hectare ou que necessitam de menos cuidados e menos mão-de-obra para a sua produção. Neste caso, a tradição local de produzir uma determinada variedade pode ser deixada de lado e dá lugar a economia de mercado, ou seja, produção em larga escala de outras cepas com custos menores.

${ }^{20}$ Enquanto na França a colheita mecanizada custa de 700 a 800 euros por hectare, o custo da colheita manual é de cerca de 2.000 euros por hectare (NIEDERLE, 2011).
} 
Se não bastassem as questões de ordem prática a serem superadas, ainda existem as de ordem técnica. Silva et al (2012) em um recente trabalho publicado aborda pelo menos quatro questões que podem obstaculizar a institucionalização das IGs no Brasil. Os autores traçam inclusive, um paralelo entre os critérios utilizados no Brasil e na União Europeia para a concessão das IGs, apontando as diferenças mais significativas:

A primeira questão importante que merece reflexão está relacionada ao sistema de certificação da produção, ou seja, o estrito cumprimento do estabelecido no caderno de normas ou regulamento de uso. Enquanto na união Europeia às entidades governamentais tem um papel fundamental nesse processo, inclusive certificando as próprias certificadoras privadas, no Brasil existem pelo menos três maneiras dos produtores controlarem sua produção na IG: controle interno, externo e autocontrole. É necessário, portanto, consolidar um sistema de certificação que valorize, concretamente, a produção agroalimentar e os artigos com qualidade diferenciada (SILVA et al. 2012).

Outro obstáculo a ser superado refere-se à dificuldade de entendimento e articulação dos diferentes Ministérios e organismos nas discussões relacionadas às IGs. É necessário clarificar o papel de órgãos como Embrapa, Sebrae, universidades, ONGs para evitar posições conflitantes que dificultam e retardam as discussões. Em alguns momentos as posições podem ser conflitantes e incapazes de construir uma aliança entre os distintos atores envolvidos (SILVA et al. 2012).

Um terceiro obstáculo relaciona-se ao aporte financeiro necessário para obtenção e manutenção de uma IG. Novamente não está clara a atribuição corresponde aos distintos órgãos envolvidos, cujas posições podem ser muitas vezes conflitantes. Na União Europeia, por exemplo, cerca de $50 \%$ das despesas dos Conselhos Reguladores referentes à promoção e divulgação de seus produtos são subvenciados pela própria União Europeia. Além disso, os produtores europeus contam com o apoio direto ou indireto de programas de desenvolvimento territorial (como o Leader ${ }^{21}$ ) e da própria Política Agrária Comunitária - PAC (SILVA et al. 2012).

Finalmente, o quarto ponto refere-se ao fato da legislação brasileira conceder Indicação de Procedência (IP) e Denominação de Origem (DO) enquanto etapas distintas de um processo de qualificação, quando, em verdade representam, ao menos juridicamente,

\footnotetext{
21 "Liaisons entre activités de Development de L'Economia Rural" - Trata-se de iniciativas de desenvolvimento rural implementadas na União Européia como ênfase no desenvolvimento de quatro grandes temas: utilização de novos conhecimentos e tecnologia, melhoria na qualidade de vida, valorização dos produtos locais, valorização dos recursos naturais e culturais, como é precisamente o caso das indicações geográficas de produtos agroalimentares (SILVA et al, 2012).
} 
instrumentos diferenciados de proteção de bens imateriais. Na prática a IP tem sido vista como uma forma de proteção mais flexível que a DO. Ocorre que, em algumas situações os produtores podem requerer uma IP e adiante uma $\mathrm{DO}^{22}$. Neste caso, a dúvida principal estaria relacionada a extinção, ou não, da IP (SILVA et al. 2012).

\section{CONSIDERAÇÕES FINAIS}

O Instituto Nacional de Propriedade Industrial (INPI) concedeu até o mês de março de 2015, quarenta e duas IGs. Destas, trinta e quatro são Indicações de Procedência (IP) e oito Denominações de Origem (DO). Embora as IGs ainda estejam em estágio embrionário no Brasil, a literatura demonstra que podem desempenhar um importante papel no estimulo ao desenvolvimento territorial rural. Incentivadas pela expansão da multifuncionalidade da agricultura, podem agregar valor aos produtos agrícolas tradicionais contribuindo, por exemplo, para amenizar efeitos do êxodo rural.

Importante lembrar que na União Europeia, IGs são amplamente utilizadas e constituem-se em um importante instrumento de valorização da cultura e do patrimônio local. Há, inclusive, movimentos para ampliar o reconhecimento de IGs de produtos agrícolas com o claro objetivo de tornar estes produtos mais competitivos no mercado.

No Brasil, embora o interesse nas IGs seja relativamente recente, existe grande potencial para desenvolvimento. Organismos como Sebrae, Ministério da Agricultura Pecuária e Abastecimento (MAPA), Embrapa e Universidades tem desenvolvido projetos importantes para fortalecer este instrumento.

Entretanto, ao analisar experiências em andamento, mesmo aquelas com mais vitalidade, observam-se problemas provocados principalmente pela maneira como foram implementadas ou estão se desenvolvendo. Na literatura, sobretudo relacionada a vitivinicultura, é possível identificar indícios de que a mercantilização pode, em alguns casos, provocar uma descaracterização da produção. Outros problemas surgem na estruturação dos arranjos institucionais. Neste caso dois pontos são fundamentais: a maneira como o arranjo é estruturado, o que pode excluir mais que incluir produtores, e a maneira como ele efetivamente atua, em muitos casos favorecendo o controle institucional, político e financeiro de grandes produtores sobre pequenos produtores.

\footnotetext{
${ }^{22}$ Fato que ocorreu recentemente com o Vale dos Vinhedos.
} 
A partir destas constatações parece evidente que a implementação de uma estratégia em busca do reconhecimento da IG para determinado produto ou serviço está longe de ser considerada simples. Adequar interesses de todos os envolvidos requer habilidade e competência da organização líder nesse processo, no caso da associação organizada que representa os atores envolvidos. É neste ambiente que emerge o importante papel dos arranjos institucionais estruturados para articular os diversos atores interessados e, nestes arranjos, o ponto nevrálgico parece ser o papel da governança que deve sempre trabalhar para que interesses coletivos estejam acima dos interesses particulares.

Neste contexto, entende-se que um papel de destaque nos processos de discussão, implementação e manutenção das IGs pode estar reservado as universidades. IGs possuem interfaces com várias áreas do conhecimento: direito, economia, agronomia, administração, engenharia ambiental entre tantas outras e as universidades, a partir de seus programas de pesquisa e extensão, podem auxiliar potencializando vantagens proporcionadas pelas IGs e amenizando os desafios impostos a elas. No entanto, para isso, as universidades necessitam ser estimuladas e apoiadas pelos organismos públicos e privados envolvidos.

\section{REFERÊNCIAS}

ANDION, C. Atuação das organizações não governamentais (ONGS) nas dinâmicas de desenvolvimento no meio rural de Santa Catarina. In. VIEIRA, P. F. et al. Desenvolvimento Territorial Sustentável no Brasil: subsídios para uma política de fomento. Florianópolis: APED: SECCO, 2010.

APROVALE - Associação dos Produtores de Vinhos Finos do Vale dos Vinhedos. Disponível www.valedosvinhedos.com.br. Acesso em 23 jun de 2012.

CALDAS, A. S.; CERQUEIRA, P. S.; \& PERIN, T. F. Mais Além dos Arranjos Produtivos Locais: as indicações geográficas protegidas como unidades de desenvolvimento local. RDE - Revista de Desenvolvimento Econômico, ano VII, n 11, Salvador - BA, Janeiro de 2005.

CARNEIRO, M. J.; ROCHA, B. N.; Limites e possibilidades da construção de territórios de desenvolvimento na região serrana do Rio de Janeiro. In. VIEIRA, P. F. et al.

Desenvolvimento Territorial Sustentável no Brasil: subsídios para uma política de fomento. Florianópolis: APED: SECCO, 2010.

CARRIÉRE, J.-P.; CAZELLA, A. A. Abordagem introdutória ao conceito de desenvolvimento territorial. EISFORIA, Florianópolis, V, 04 p. 23-47, Dez. 2006. 
CRUZ, M. C.; SLUSZZ, T.; TAPIAS, B. A. \& PEZZINI, T. G.; Análise de pedidos de indicação geográfica para definição de critérios que possam contribuir para a competitividade do agronegócio brasileiro. Disponível em www.cnpma.embrapa.br/.../Analise_Pedidos_Indica_Geograficas.pdf s.d.

DULLIUS, P. R.; Indicações geográficas e desenvolvimento territorial: as experiências do Rio Grande do Sul. Dissertação de mestrado apresentada ao Programa de Pós Graduação em Extensão Rural da Universidade de santa Maria. Santa Maria -RS. 2009.

FROEHLICH, J. M.; DULLIUS, P. R.; LOUZADA, J. A.; \& MACIEL, C. R.; A agricultura familiar e as experiências de indicações geográficas no Brasil meridional. Agrociencia Uruguay. Volumen 14 2:115-125. Julio-diciembre. 2010.

GIL, A. C.; Como elaborar projetos de pesquisa. Editora Atlas, 5ª edição. São Paulo -SP. 2010.

JEAN, B. Do desenvolvimento Regional ao desenvolvimento territorial sustentável: rumo a um desenvolvimento territorial solidário para um bom desenvolvimento dos territórios rurais. In. VIEIRA, P. F. et al. Desenvolvimento Territorial Sustentável no Brasil: subsídios para uma política de fomento. Florianópolis: APED: SECCO, 2010.

MARTINI, G.; População, Meio Ambiente e Desenvolvimento. Verdades e contradições. Editora da Unicamp. Campinas - SC. 1993.

MARTINI, G.. A trajetória da modernização agrícola: a quem beneficia?. Lua Nova: cultura e política, n23. 1991.

MOREIRA, R. M.; CARMO, M. S.; Agroecologia na construção do desenvolvimento rural sustentável. Agric. São Paulo, v. 51, n. 2, p. 37-56, jul/dez. 2004.

NIEDERLE, P. A. Controvérsias sobre a noção de indicações geográficas enquanto instrumento de desenvolvimento territorial: a experiência do Vale dos Vinhedos em questão. $47^{\circ}$ Congresso da Sociedade Brasileira de Economia, Administração e Sociologia Rural. Porto Alegre - RS, 2009.

NIERDERLE, P. A. Indicações Geográficas, inovação e tipicidade: uma "dessingularização" dos terroirs vitivinícolas? IX Reunião de Antropologia do Mercosul. Curitiba - PR, 2011.

PECQUEUR, B.; O desenvolvimento territorial: uma nova abordagem dos processos de desenvolvimento para as economias do sul. Raízes, Campina Grande, Vol. 24 n. 01 e 02, p. $10-22$, jan/dez 2005.

PROGOETHE - Associação dos Produtores da uva e do Vinho Goethe de Urussanga/SC. Disponível em www.progoethe.com.br. Acesso em 04 jun 2012.

RAUPP, F. M.; BEUREN, I. M.; Metodologia da pesquisa aplicada ás ciências sociais. In BEUREN, Ilse Maria et al. Como elaborar trabalhos monofráficos em contabilidade: teoria e prática. Editora Atlas. São Paulo -SP, 2003. 
SACCO DOS ANJOS, F.; VELLEDA CALDAS, N.; Indicaciones geográficas, desarrollo e identidad territorial: el caso de Vale dos Vinhedos em el sur de Brasil. Agricultura Familiar em España. 2010.

SACHS, I.; Inclusão social pelo trabalho - Desenvolvimento humano, trabalho descente e o futuro dos empreendedores de pequeno porte. Rio de Janeiro: Gramond. 2003.

SILVA, F. N.; SACCO DOS ANJOS, F.; CALDAS, N. V.; POLLNOW, G. E.; Desafios à Institucionalização das Indicações Geográficas no Brasil. Revista Desenvolvimento Regional em debate. Ano 2. No 2, Nov. 2012.

VEIGA, J. E.; A relação urbano / rural no desenvolvimento regional. Cadernos do CEAM. Volume 17. Universidade de Brasília-DF. 2005.

VELLOSO, C. Q.; Indicação geográfica e desenvolvimento territorial sustentável: a atuação dos atores sociais nas dinâmicas de desenvolvimento territorial a partir da ligação do produto ao território (um estudo de caso em Urussanga - SC). Dissertação do Programa de Pós Graduação em Agroecossistemas. UFSC. Florianópolis -SC, 2008.

VIEIRA, P. F.; CUNHA, I. Posfácio. Repensando o desenvolvimento catarinense. In VIEIRA, P. F. (Org). A pequena produção e o modelo catarinense de desenvolvimento. Florianópolis: APED, 2002. 